\title{
Assessment of potential sites for a non-linear mooring system in floating offshore wind applications
}

\author{
F. Khalid **, P.R. Thies \& L. Johanning * \\ College of Engineering, Mathematics and Physical Sciences, University of Exeter, Penryn Campus, UK \\ "Naval Architecture and Ocean Engineering, Harbin Engineering University, Harbin, China \\ ** Corresponding author
}

D. Newsam

Intelligent Mooring, Intelligent Moorings Limited, Denbighshire, UK

\begin{abstract}
Effective station-keeping of turbines across a range of environmental conditions is critical for the development of the floating wind industry. This paper investigates the influence of environmental conditions and water depth at the deployment site on the load reduction potential of the Intelligent Mooring System (IMS), a non-linear mooring component. The IMS is modelled as part of the mooring system for the OC4 semi-submersible Floating Wind Turbine (FWT) using a FAST-OrcaFlex interface. Site-specific metocean parameters from the ECMWF database are used to calculate mooring loads at FWT deployed at two sites with variable depth, with and without the IMS as part of the mooring system to assess its load reduction potential. The results indicate that the IMS has a larger load reduction potential in shallow water depth. This mooring design could thus address the design challenges for shallow water floating wind farms currently.
\end{abstract}

\section{INTRODUCTION}

Deployment of bottom-fixed offshore wind turbines is limited to shallow water sites (WindEurope Business Intelligence, 2019) due to techno-economic limitations. However, the nascent floating wind sector provides the potential to harness the improved wind resource further offshore in deep water locations. The global market projections for floating offshore wind by the Carbon Trust (2018) range up to $29 \mathrm{GW}$ installed capacity by 2030 . This level of deployment translates to thousands of individual installations and will only be realised if existing challenges are adequately addressed to reduce the Levelised Cost of Energy (LCoE). For various FWT concepts, LCoE displays high dependence on the site depth and distance to shore, due to cost associate with moorings and export cables, respectively (Myhr et al., 2014). A large number of mooring lines will have to be deployed and maintained for effective station keeping of the FWT fleet during its design lifetime.

The floating wind industry currently adopts various combinations of conventional mooring configurations and materials from the oil and gas industry. The mooring design is de-risked by employing conservative design practices, thereby, providing an opportunity for improvement in the cost-performance trade-off.

Innovative mooring solutions have been proposed by existing research to suggest the use of non-linear materials (Weller et al., 2015) and hybrid systems
(Gordelier et al., 2015; Thies et al., 2014). A suitable mooring system must resist environmental and operational loads as well as farm effects during operational and extreme conditions. Non-linear mooring components provide the benefit of providing necessary compliance to reduce line tension whilst ensuring effective station-keeping during extreme conditions.

The IMS is one such non-linear mooring component based on hydraulic load dampening mechanisms. It is composed of a fluid-filled bladder housed in braided rope and connected to an accumulator. The performance of the IMS is similar to a shock absorber: increased mooring line loads result in IMS rope extension that reduces the volume of the internal bladder. This increases the pressure in the bladder and transfers fluid to the accumulator. At the end of a loading event, the braided rope retracts and the fluid stored in the accumulator is returned to the bladder due to a decrease in the system pressure. Active control of the system pressure provides intelligent stiffness variation that can be tuned to suit the prevailing metocean conditions. Further details about the system are presented in previous work (Harrold et al., 2018, 2019; Harrold et al, 2020; Luxmoore et al., 2016).

The feasibility of deployment sites can be characterised by a range of site characteristics including the metocean and bathymetric parameters (Carbon Trust, 2008). Insight into site load characterization informs design optimization, however, a comprehensive load assessment, in the time-domain, cannot be per- 
formed for all variables at an early design stage since it is computationally expensive (Vorpahl et al., 2013).

Numerical investigations have shown that the IMS can reduce peak mooring line loads by up to $40 \%$ for a site in the North Sea (Harrold et al., 2020).

This paper presents a wider numerical investigation into the load reduction potential of a hybrid mooring system incorporating the IMS for various operational and parked load cases using a reduced scatter plot. A comparative assessment in two different water depths is conducted for the same environmental conditions to evaluate the influence of depth on the load reduction potential of the IMS. A second study is conducted using site specific environmental conditions for the dominant load case to highlight the combined influence of depth and environmental parameters on the load reduction potential.

\section{METHODOLOGY}

Two studies are conducted as presented in this paper:

- Study 1 utilises established numerical modelling tools to simulate loads on a multimegawatt FWT for two sites with the same environmental conditions but different depths. This allows for the modelling of an adjusted mooring system based on site depth and allows for the identification of the dominant load case.

- Study 2 presents an analysis of load reduction for the dominant load cases at two sites (of varying depths) using site specific modelled metocean data to identify the combined influence of depth and environmental parameters on IMS load reduction capabilities.

\subsection{Numerical modelling tools}

The turbine structure and environmental parameters are modelled in FAST and OrcaFlex using the OrcaFAST coupling DLL distributed as part of FAST v8.

FAST (2016), a computer aided engineering design code developed by NREL, is suitable for determination of loads on offshore wind turbines. It couples well-defined data exchange interfaces (corresponding to various physical domains) under a modularisation framework to model a coupled nonlinear aero-hydro-servo-elastic system. Improved modeling fidelity can be achieved through the use of finite element mooring theory. OrcaFlex, an industry standard software package for analysis of offshore structures, is widely used to model the effective tension in multi-member mooring lines.

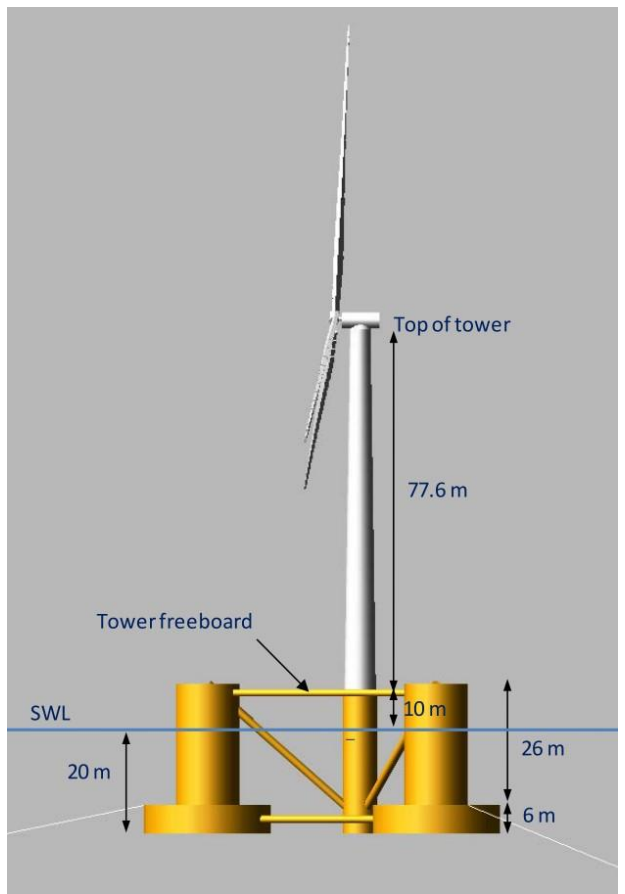

Figure 1 Diagrammatic representation of the OC4 semisubmersible (Robertson et al., 2014).

The interface to OrcaFlex allows platform motions from FAST to be passed to OrcaFlex and vice versa for the hydrodynamic and mooring loads.

\subsection{Turbine and platform specification}

The selected device is a 5MW three-bladed, geared upwind turbine with yaw capability developed by NREL as described by Jonkman et al. (2009). A variable speed device with variable blade-pitch-tofeather control, this turbine was designed to be representative of the large 5-10 MW class turbines. It is largely based on the REpower (now Senvion) $5 \mathrm{MW}$ turbine and has been widely used in research as the baseline for offshore turbines to provide robust results for loading regimes. The turbine has a rated speed of $11.4 \mathrm{~m} / \mathrm{s}$ and cut-in and cut-out speeds of 3 $\mathrm{m} / \mathrm{s}$ and $25 \mathrm{~m} / \mathrm{s}$, respectively.

The detailed parameters of the OC4 semisubmersible platform, developed for the DeepCwind project for use in conjunction with the NREL $5 \mathrm{MW}$ turbine, are reported previously (Robertson et al., 2014) . The semi-submersible is composed of a main column attached to the turbine tower and three offset columns as seen in Figure 1.

\subsection{Mooring configuration}

The baseline design of the platform consists of a 3point catenary mooring system, where each line is connected to one of the three offset columns. The fairleads are located at the top of the offset columns, $14 \mathrm{~m}$ below the mean sea level. The mooring system is modelled for deployment at a depth of $200 \mathrm{~m}$ and the anchors are fixed in the inertial frame of 


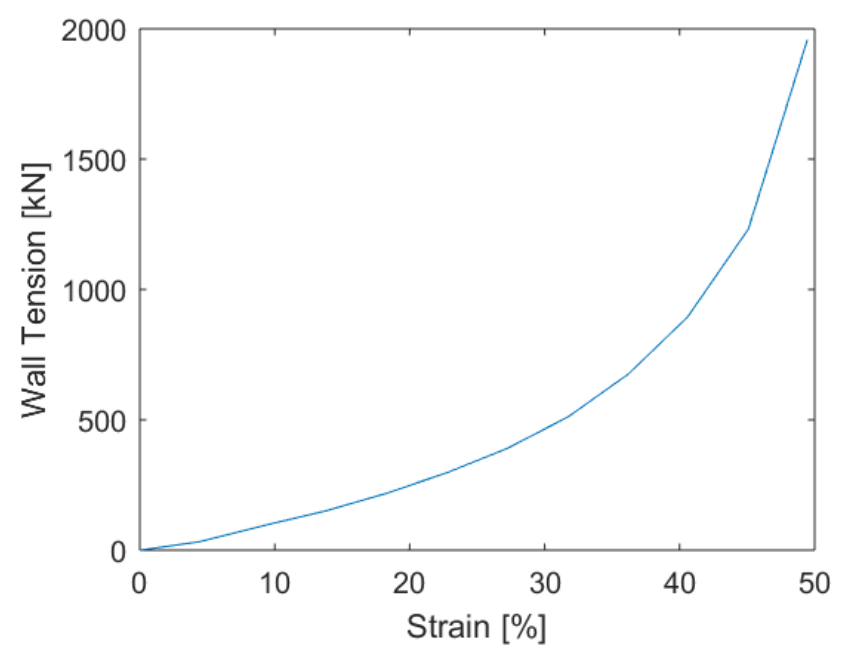

Figure 2 Load extension curve of the $163 \mathrm{kPa}$ pre-charge IMS unit used for IMS stiffness characterisation.

reference at a radius of $837.6 \mathrm{~m}$ from the platform centerline. All lines, fairlead and anchor, are $120^{\circ}$ apart relative to the equilibrium position of the platform. The present paper assumes that the fairleads are kept the same as originally defined by Robertson et al. (2014).

Each mooring line has a length and diameter of $835.5 \mathrm{~m}$ and $0.08 \mathrm{~m}$, respectively. The baseline mooring material has a linear density of $113.4 \mathrm{~kg} / \mathrm{m}$ and axial stiffness of $753.6 \mathrm{MN} / \mathrm{m}$.

The method established by Harrold et al. (2018) is used to adapt the baseline mooring system to introduce a triple-unit IMS component in each mooring line. The triple unit is composed of three bladders, each housed in braided rope and connected in parallel, and a single accumulator with an increased capacity. A $2.67 \mathrm{~m}$ segment of the baseline material in each mooring line is replaced with the IMS at the platform-end to model the braided rope segment of the triple unit. This has an associated diameter of 0.3 $\mathrm{m}$ and a linear density of $70.7 \mathrm{~kg} / \mathrm{m}$. For this study, the non-linear stiffness characteristics of the IMS are defined by a single load-extension curve, hence the potential for controlled stiffness variability is not investigated here. This load extension curve, presented in Figure 2, is based on testing performed for a 163 $\mathrm{kPa}$ pre-charge configuration and is reported previously (Harrold, 2019).

\subsection{Site depth characterisation}

To investigate the influence of the variation of depth on the load reduction capability of the IMS, the baseline and IMS models are adapted for a site with reduced water depth but the same metocean characterisation. Four cases at two sites are identified: Site A (200 m depth) and Site B (100 m) depth for a mooring system with and without the IMS component as shown in Table 1.

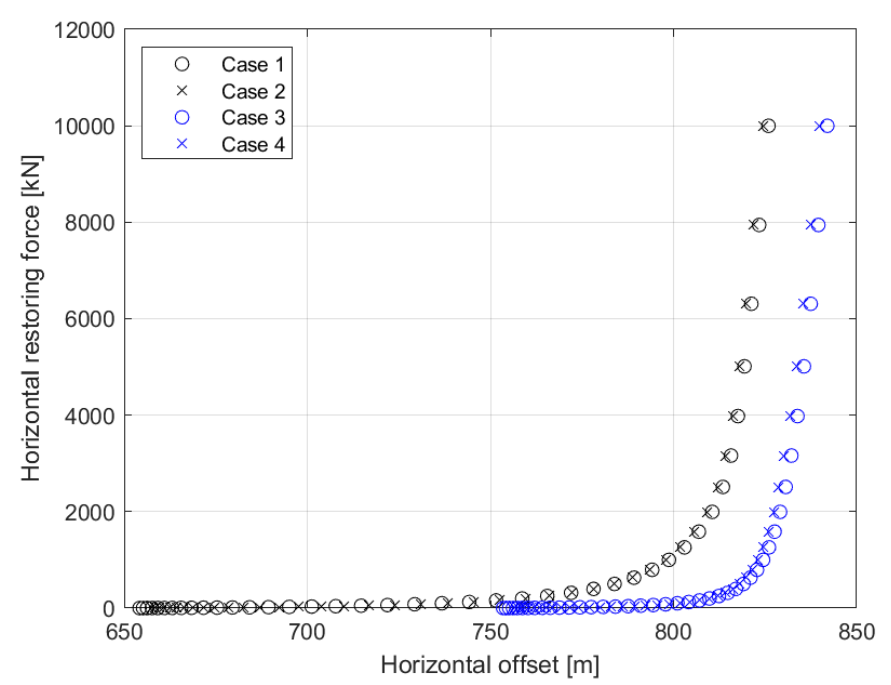

Figure 3 Horizontal restoring force and offset for the OC4 model cases.

Table 1. Summary input data for turbines deployed at Site $A$ and Site B

\begin{tabular}{|c|c|c|c|}
\hline & Site & Depth (m) & IMS mooring component \\
\hline $\begin{array}{l}\text { Case } 1 \\
\text { Case } 2 \\
\end{array}$ & A & 200 & $\begin{array}{l}\text { No } \\
\text { Yes }\end{array}$ \\
\hline $\begin{array}{l}\text { Case } 3 \\
\text { Case } 4\end{array}$ & $\mathrm{~B}$ & 100 & $\begin{array}{l}\text { No } \\
\text { Yes }\end{array}$ \\
\hline
\end{tabular}

Case 1 is the baseline scenario and Case 2 includes the IMS segment at a water depth of $200 \mathrm{~m}$, whereas, Case 3 and Case 4 are the baseline and IMS models at a water depth of $100 \mathrm{~m}$, respectively. All four cases are run for both the studies presented in this paper.

The mooring system is adjusted for the reduced depth $(100 \mathrm{~m})$ whilst ensuring that the mooring configuration is maintained. Effective tension at the fairlead of all mooring lines in the $200 \mathrm{~m}$ baseline is calculated using the static convergence. The seabed depth is then adjusted to $100 \mathrm{~m}$ and the anchor positions are adjusted to maintain the catenary configuration with the same overall line length. The resulting horizontal restoring force and offset for each modelled case is displayed in Figure 3.

Clearly, the horizontal distance between fairlead and the touchdown increases as the restoring force applied to the mooring line at the fairlead increases. A longer length of chain is required to withstand the increased restoring force applied at the fairlead.

\subsection{Site environmental characteristics}

For Study 1, lumped load cases (Kühn, 2001) are adopted from the reduced scatter of the K13 shallow water site of the Upwind Design Basis (Fischer et al., 2010). This lumped data has been used extensively in load investigations of fixed offshore wind turbines (Aasen et al., 2017; Løken, 2009; Ziegler, 2016). Lumping of sea states provides a good estimate of damage for all load cases with increased computational efficiency. 
The significant wave height $\left(H_{S}\right)$, wind speed at hub height $\left(V_{t}\right)$, peak wave period $\left(T_{p}\right)$ and turbulence intensity $(T I)$ are described for each load case as seen in Figure 4. For LC17, the prescribed wind speed range is excluded and the mean wind speed of $38 \mathrm{~m} / \mathrm{s}$ is chosen for simulating loads.

For Study 2, a 10 year ECMWF data record from January 2008 to December 2017 was extracted for the wind speed with the highest load. An $H_{s}-T_{p}$ scatter for the wind speed provided information on the load cases to be simulated for accurate representation of the site load conditions.

For each load case (lumped or otherwise), a full field wind mesh was generated using a Kaimal distribution in the NREL preprocessing tool, TurbSim (2006). For each 10 minute period, the wind and waves are assumed to be unidirectional (no directional spreading is introduced) and aligned.

Table 2. Lumped load cases for site environmental characterisation (Fischer et al., 2010).

\begin{tabular}{lllll}
\hline LC & $\begin{array}{l}V_{t} \\
(\mathrm{~m} / \mathrm{s})\end{array}$ & $\begin{array}{l}H_{s} \\
(\mathrm{~m})\end{array}$ & $\begin{array}{l}T_{p} \\
(\mathrm{~s})\end{array}$ & $\begin{array}{l}T I \\
(\%)\end{array}$ \\
\hline 1 & 2 & 1.07 & 6.03 & 29.2 \\
2 & 4 & 1.1 & 5.88 & 20.4 \\
3 & 6 & 1.18 & 5.76 & 17.5 \\
4 & 8 & 1.31 & 5.67 & 16 \\
5 & 10 & 1.48 & 5.74 & 15.2 \\
6 & 12 & 1.7 & 5.88 & 14.6 \\
7 & 14 & 1.91 & 6.07 & 14.2 \\
8 & 16 & 2.19 & 6.37 & 13.9 \\
9 & 18 & 2.47 & 6.71 & 13.6 \\
10 & 20 & 2.76 & 6.99 & 13.4 \\
11 & 22 & 3.09 & 7.4 & 13.3 \\
12 & 24 & 3.42 & 7.8 & 13.1 \\
13 & 26 & 3.76 & 8.14 & 12 \\
14 & 28 & 4.17 & 8.49 & 11.9 \\
15 & 30 & 4.46 & 8.86 & 11.8 \\
16 & 32 & 4.79 & 9.12 & 11.8 \\
17 & 38 & 4.9 & 9.43 & 11.7 \\
\hline
\end{tabular}

This leads to the linear addition of the aero- and hydrodynamic loads. The stationary wind and wave fields result in stationary load characterisation, therefore, the initialization parameters for the FAST controller (blade pitch angles, pitch control mode, rotor speed and generator activity) are adjusted for the ambient wind speed as summarised by Khalid (2019).

\section{RESULTS}

\subsection{Study 1}

\subsubsection{Metocean parameters and turbine operation}

Sample environmental parameters and associated wind turbine generator speed for the load cases in Case 1 of Study 1 can be seen in Figure 4.

It can be observed that the turbine is operational for all load cases between LC02 and LC12 (inclusive), therefore, the FAST initialization parameters have successfully modelled a parked and operational turbine for the respective load cases.

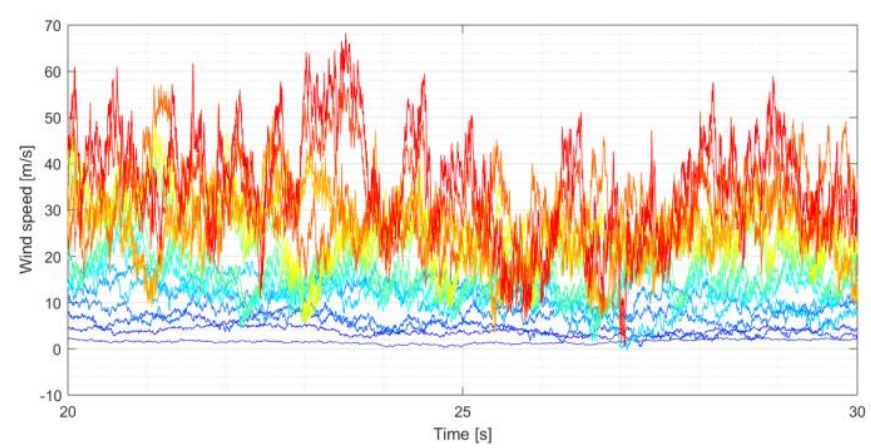

(a) Wind speed output by FAST

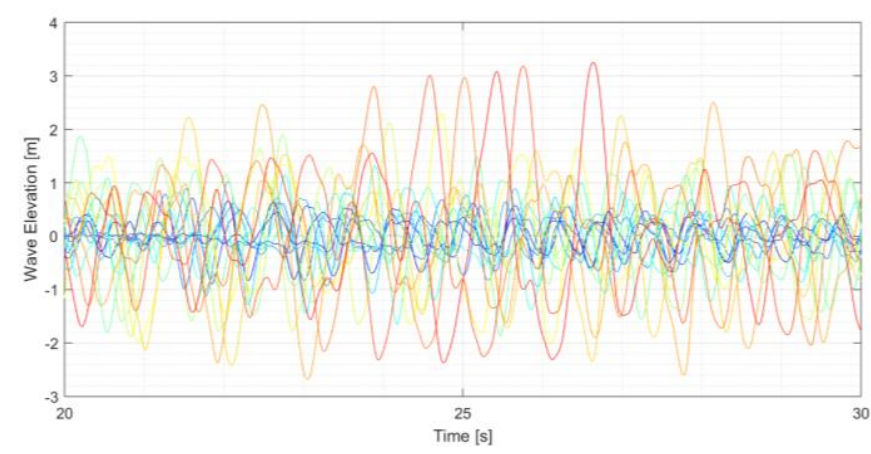

(b) Wave elevation output by OrcaFlex

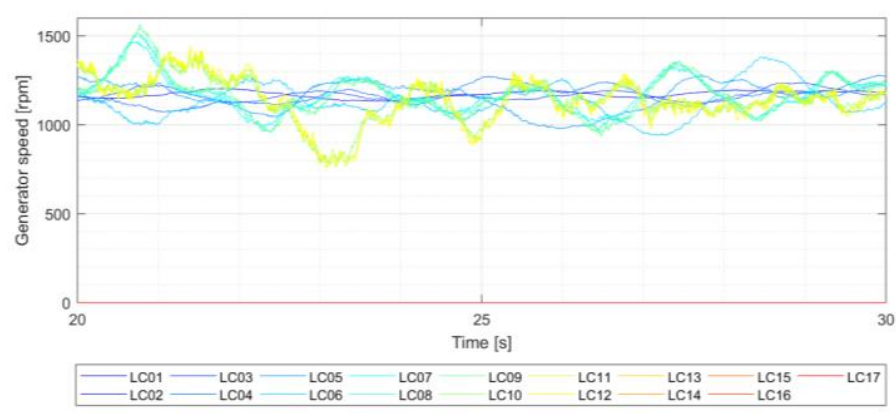

(c) Turbine operation output by FAST

Figure 4 Wind speed, wave elevation and generator rotation of the NREL 5 WM offshore wind turbine simulated for Case 1 in Study 1.

\subsubsection{Dynamic response of baseline model}

The dynamic response of the mooring system is presented by the effective tension of the upwind line at the fairlead as shown in Figure 5 for Case 1 of Study 1. 


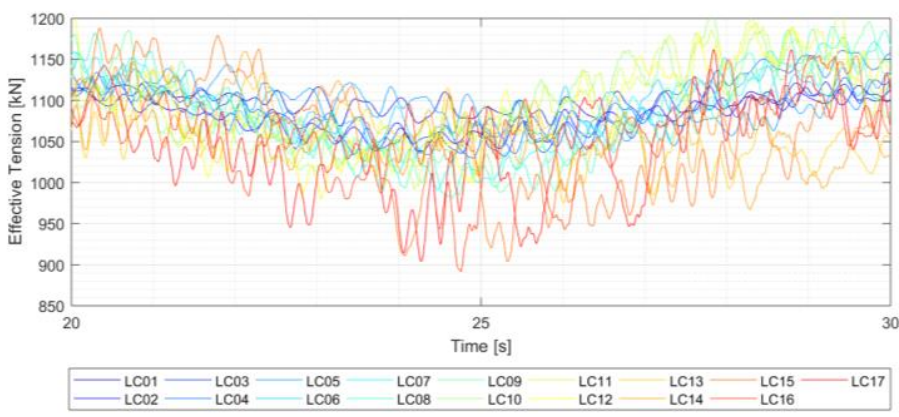

Figure 5 Effective tension at fairlead of upwind mooring line of the OC4 semi-submersible simulated for Case 1 in Study 1.

It can be observed that for the increase in wind speed, the effective tension at the fairlead has a larger range of variation which may contribute to increased fatigue damage.

\subsubsection{IMS load reduction potential}

To demonstrate the load reduction potential of the IMS, sample load time series are presented in Figure 6 for Case 1 and Case 2 for LC06. The mooring line loads are seen to be modulated by including the IMS in the system.

To quantify the load reduction potential of the IMS, the percentage of load reduction is calculated for each load case in Table 2. A comparative analysis between Case $1 \& 2$ (depth $=200 \mathrm{~m})$ and Case 3 $\& 4($ depth $=100)$ for Study 1 are shown in Figure 7 . It can be observed that the IMS reduces the loads at the fairlead of the upwind mooring line at both sites with a similar mean value of approximately $2.5 \%$. However, the load peaks at the shallower site $(100 \mathrm{~m}$ depth) experience a reduction of up to $30 \%$ relative to $9 \%$ for the deep water site (200m depth).

It is also observed that the maximum load reduction is observed for the wind speed bins near the rated speed $(10-12 \mathrm{~m} / \mathrm{s})$ and for higher speeds of 25 $\mathrm{m} / \mathrm{s}$.

\subsection{Study 2}

\subsubsection{Metocean parameters}

Study 2 utilises ECMWF data for two sites in the North Sea with the properties shown in Table 3.
The ECMWF data is previously shown (Khalid, 2019) to provide better agreement with other metocean models for the medium wind speeds, therefore, the wave parameters for wind speed of 10 $-12 \mathrm{~m} / \mathrm{s}$ are extracted from the ten year data. Figure 8 shows the occurrence probability of different wave conditions for the $11 \mathrm{~m} / \mathrm{s}$ wind speed bin at Site A.

Additional bins are identified from Site B and the OC4 semi-submersible model is run for all four cases listed in Table 1.

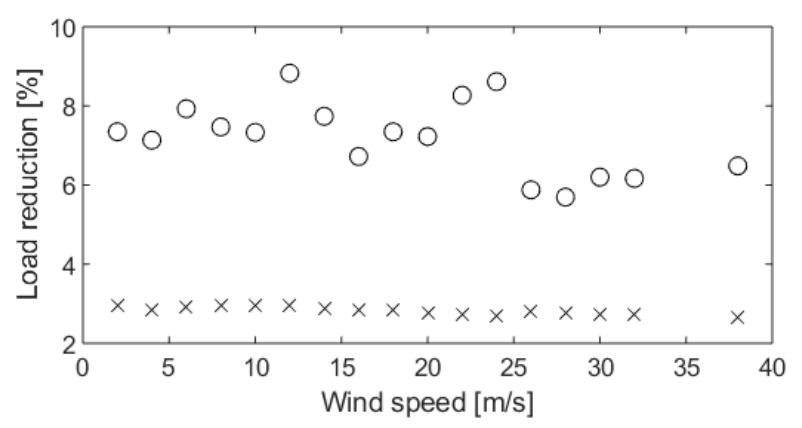

(a) IMS load reduction at $200 \mathrm{~m}$ depth

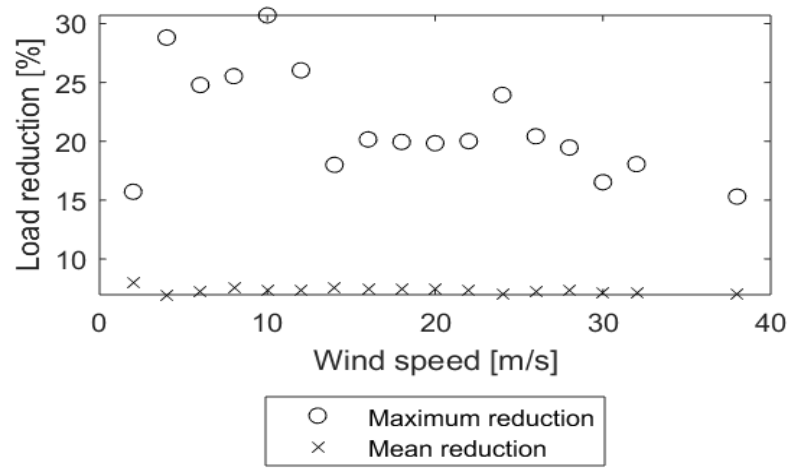

(b) IMS load reduction at $100 \mathrm{~m}$ depth

Figure 7 IMS load reduction potential at $200 \mathrm{~m}$ and $100 \mathrm{~m}$ depth for various load cases.

Table 3 Description of sites chosen for Study 2.

\begin{tabular}{lllll}
\hline Site & Location & Depth $(\mathrm{m})$ & Latitude & Longitude \\
\hline $\mathrm{A}$ & $\begin{array}{l}\text { Northern } \\
\text { North Sea }\end{array}$ & 200 & $58.5^{\circ} \mathrm{N}$ & $0^{\circ}$ \\
\hline $\mathrm{B}$ & $\begin{array}{l}\text { Central } \\
\text { North Sea }\end{array}$ & 100 & $55.5^{\circ} \mathrm{N}$ & $0.75^{\circ} \mathrm{E}$ \\
\hline
\end{tabular}

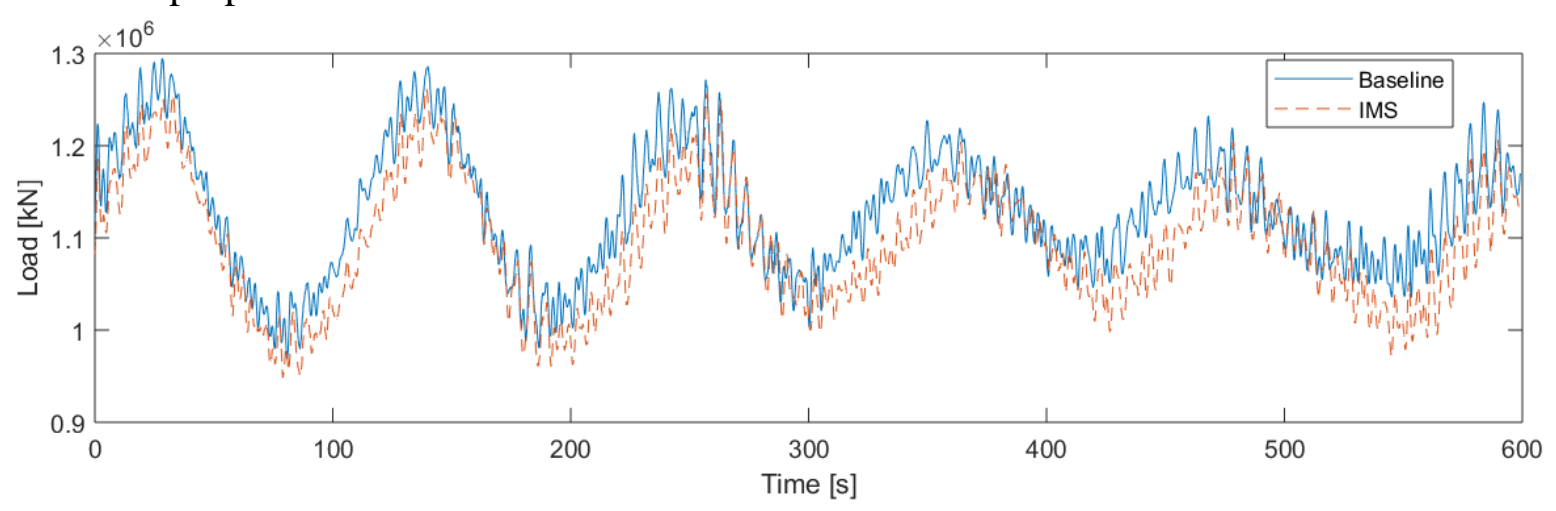

Figure 6 Load time series for LC06 for the baseline mooring system and with the IMS included. 


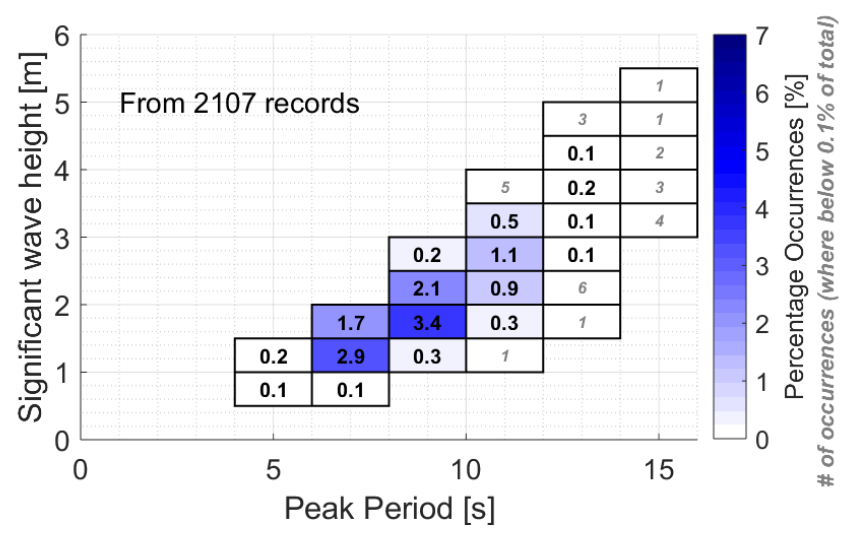

Figure 8 Wave height and peak period characterisation of Site A for a wind speed of $11 \mathrm{~m} / \mathrm{s}$.

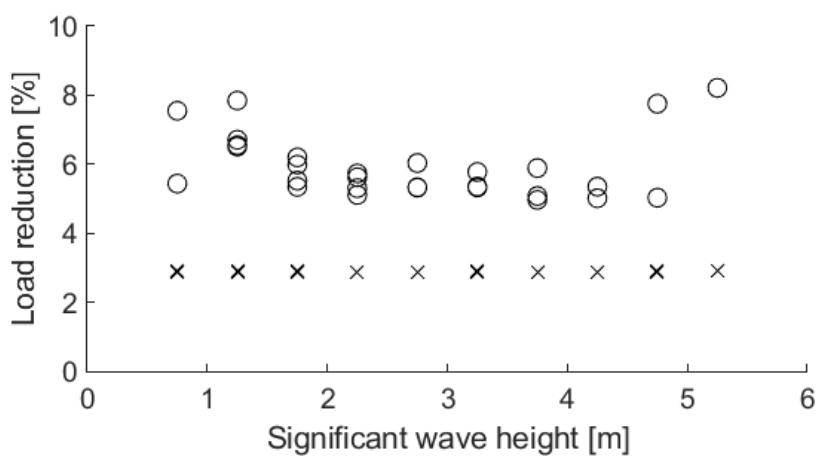

(a) IMS load reduction at $200 \mathrm{~m}$ depth

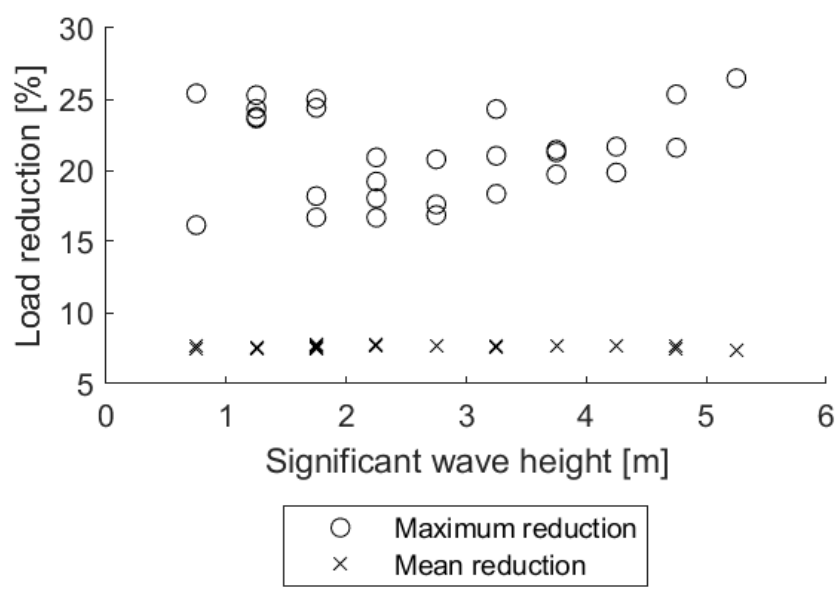

(b) IMS load reduction at $100 \mathrm{~m}$ depth

Figure 9 IMS load reduction for Site A and Site B using site specific data for Study 2.

\subsubsection{IMS load reduction potential}

The IMS load reduction potential is quantified for Site A and Site B for 28 different combinations of wave parameters for the $11 \mathrm{~m} / \mathrm{s}$ wind speed bin. The mean load reduction is shown in Figure 9.

It can be observed that the mean load reduction for Site B is higher than Site A: the deep water site displays a mean peak reduction of $8 \%$ relative to $20 \%$ at the shallow water site for all seastates prevalent at wind speeds of $11 \mathrm{~m} / \mathrm{s}$. As the load reduction potential is only characterised for a wind speed of 11 $\mathrm{m} / \mathrm{s}$, Study 2 is representative of LC05 and LC06 from Study 1.

\section{DISCUSSION}

This paper compares the load reduction potential of the IMS for sites with varying water depths through 2 studies. For Study 1, both sites are characterized with the same metocean conditions to study the influence of depth on the load reduction only. Results indicate that the mean load reduction potential of the IMS at both sites is similar (2\%) for individual load cases. However, the maximum load reduction potential of the IMS increases threefold at shallow water sites of about $100 \mathrm{~m}$ relative to deep water sites of $300 \mathrm{~m}$.

Study 2 investigates the influence of the water depth in conjunction with the site-specific metocean conditions for a $2 \mathrm{~m} / \mathrm{s}$ wind bin around the rated turbine speed. The overall peak load reduction for both sites is similar to that for LC05 and LC06 from Study 1. Within the same wind speed bin in Study 2, the load reduction potential of the IMS can vary by $10 \%$ based on the prevalent wave conditions. This leads to the argument that site-specific load characterization studies are essential to fully estimate the load reduction potential offered by the IMS over the FWT lifetime.

With a peak load reduction potential of up to $30 \%$ at the shallow water site, the IMS provides a suitable option to improve the system reliability. The risk to device survivability in case of a mooring system failure can be reduced by using the IMS. Due to the technical feasibility of installing the IMS with the complete mooring system, no additional installation costs will be incurred. Although the cost of mooring components has a linear relationship with the minimum breaking load (Harris et al., 2004), the technical and performance characteristics associated to the components are the main deciding factors in the industry.

The chosen wind speed bin of $11 \mathrm{~m} / \mathrm{s}$ provides a good estimate of operational loads experienced at the fairlead due to a combination of the operational and environmental loading. However, a more comprehensive estimate of the load reduction potential of the IMS will require an assessment of the contribution of other wind speeds to mooring line loads.

It should be noted that the results of this research are specific to the considered platform and site. Future work will investigate different platforms and sites to understand the influence of incorporating the IMS into a floating wind mooring system. 


\section{ACKNOWLEDGEMENT}

The research was undertaken as part of a collaborative project between Intelligent Mooring Systems Ltd and the University of Exeter supported by the Carbon Trust's Floating Wind Technology Acceleration Competition which is funded by the Scottish Government and supported by the Carbon Trust's Floating Wind Joint Industry Project (FLW JIP). The second author would like to acknowledge the funding through the EPSRC Supergen ORE Hub [EP/S000747/1]. The authors would also like to thank Orcina Ltd. for providing OrcaFlex and NREL for making the model FAST glue code freely available.

\section{REFERENCES}

Aasen, S., Page, A. M., Skjolden Skau, K., \& Nygaard, T. A. (2017). Effect of foundation modelling on the fatigue lifetime of a monopile-based offshore wind turbine. Wind Energy Science, 2(2), 361-376.

Carbon Trust. (2008). Offshore wind power: big challenge, big opportunity.

Carbon Trust. (2018). Floating Wind Joint Industry Project Phase I Summary Report.

Fischer, T., de Vries, W., \& Schmidt, B. (2010). Upwind Design Basis - WP4: Offshore Foudations and Support Structures.

Gordelier, T., Parish, D., Thies, P., \& Johanning, L. (2015). A Novel Mooring Tether for HighlyDynamic Offshore Applications; Mitigating Peak and Fatigue Loads via Selectable Axial Stiffness. Journal of Marine Science and Engineering, 3(4), 1287-1310.

Harris, R. E., Johanning, L., \& Wolfram, J. (2004). Mooring systems for wave energy converters : A review of design issues and choices. 3rd International Conference on Marine Renewable Energy, $1-10$. https://doi.org/10.1016/j.renene.2014.10.063

Harrold, M. J., Thies, P. R., Johanning, L., Newsam, D., \& Checkley, M. (2018). Dynamic load reduction and station keeping mooring system for floating offshore wind. IOWTC.

Harrold, M. J., Thies, P. R., \& Newsam, D. (2019). Modeling a non-linear mooring system for floating offshore wind using a hydraulic cylinder analogy. OMAE.

Harrold, M. J., Thies, P. R., Newsam, D., Ferreira, C. B., \& Johanning, L. (2020). Large-scale testing of a hydraulic non-linear mooring system for floating offshore wind turbines. Ocean Engineering, 206(April).

Jonkman, B., \& Buhl, M. L. (2006). TurbSim User's Guide.

Jonkman, B. J., \& Jonkman, J. (2016). FAST v8.16.00a-bjj.

Jonkman, J., Butterfield, S., Musial, W., Scott, G., Jonkman, J., Butterfield, S., Musial, W., \&
Scott, G. (2009). Definition of a 5-MW Reference Wind Turbine for Offshore System Development (Issue February).

Khalid, F. (2019). Reliability assessment approach through geospatial mapping for offshore wind energy. University of Exeter.

Kühn, M. (2001). Dynamics and design optimization of offshore wind conversion systems. Technische Universiteit Delft.

Løken, I. B. (2009). Dynamic Response of Offshore Wind Turbines. Wind Engineering, 17(5), 238246.

Luxmoore, J. F., Grey, S., Newsam, D., \& Johanning, L. (2016). Analytical performance assessment of a novel active mooring system for load reduction in marine energy converters. Ocean Engineering, 124.

Myhr, A., Bjerkseter, C., Ågotnes, A., \& Nygaard, T. a. (2014). Levelised cost of energy for offshore floating wind turbines in a life cycle perspective. Renewable Energy, 714-728.

Robertson, A., Jonkman, J., Masciola, M., \& Song, H. (2014). Definition of the Semisubmersible Floating System for Phase II of OC4.

Thies, P. R., Johanning, L., \& McEvoy, P. (2014). A novel mooring tether for peak load mitigation: Initial performance and service simulation testing. International Journal of Marine Energy, 7, 43-56.

Vorpahl, F., Schwarze, H., Fischer, T., Seidel, M., \& Jonkman, J. (2013). Offshore wind turbine environment, loads, simulation, and design. Wiley Interdisciplinary Reviews: Energy and Environment, 2(5), 548-570.

Weller, S. D., Johanning, L., Davies, P., \& Banfield, S. J. (2015). Synthetic mooring ropes for marine renewable energy applications. Renewable Energy, 83, 1268-1278.

WindEurope Business Intelligence. (2019). Offshore Wind in Europe - Key trends and statistics 2018.

Ziegler, L. (2016). Fatigue reassessment for lifetime extension of offshore wind monopile substructures. Journal of Physics: Conference Series, November. 